\title{
Anexo 1 - Materiais e endopróteses para tratamento endovascular dos aneurismas da aorta abdominal
}

Eduardo Keller SAADI, André Severo MACHADO

Anexo1- Material necessário e endopróteses disponíveis para cirurgia endovascular de aorta

\begin{tabular}{|c|c|c|c|}
\hline Quantidade & Material & Descrição & Fornecedor \\
\hline 2 unidades de cada & 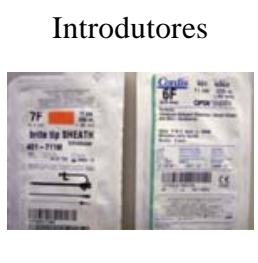 & $\begin{array}{c}\text { 1)5F, } 6 \mathrm{~F}, 7 \mathrm{~F}, 8 \mathrm{~F}, 9 \mathrm{~F}, 10 \mathrm{~F} \text {, com comprimento de } \\
11 \mathrm{~cm} \text {, com válvula, extensão lateral com torneira e } \\
\text { ponta brite tip para fio guia } 0,035 \mathrm{in} \\
\text { 2)8F, 9F, } 10 \mathrm{~F} \text {, com comprimento de } 23 \mathrm{~cm} \text {, com } \\
\text { válvula, extensão lateral com torneira e ponta brite } \\
\text { tip, para fio guia } 0,035 \mathrm{in}\end{array}$ & $\begin{array}{l}\text { Cordis } \\
\text { Boston }\end{array}$ \\
\hline 2 unidades de cada & Seringa insufladora & $\begin{array}{c}\text { Com manômetro, seringa para insuflar balão de } \\
\text { angioplastia }\end{array}$ & Medtronic \\
\hline 2 unidades de cada & Laço & $\begin{array}{l}\text { Sensation- laço em forma oval, diâmetro de } 30 \mathrm{~mm} \text {, } \\
\text { comprimento total } 240 \mathrm{~cm}\end{array}$ & Boston \\
\hline 2 unidades de cada & Fio guia & $\begin{array}{l}\text { 1)Fio guia teflonado, revestido de PTFE, ponta “J” } \\
\text { flexível de } 3 \mathrm{~cm} \text {, calibre } 0,035 \mathrm{in} \text {, com comprimento } \\
\text { de } 260 \mathrm{~cm} \\
\text { 2)Amplatz super Stiff- fio guia de duro torque, } \\
\text { ponta “J” flexível de } 3 \mathrm{~cm} \text {, calibre } 0,035 \mathrm{in} \text {, com } \\
\text { comprimento de } 260 \mathrm{~cm} \\
\text { 3)Landerguist-fio guia super rigido ,ponta } \\
\text { "J”flexível, calibre 0,035in, com comprimento de } \\
\text { 260cm-extra-stiff }\end{array}$ & $\begin{array}{l}\text { Boston } \\
\text { Promedon } \\
\text { Medtronic } \\
\text { Boston } \\
\text { CooK }\end{array}$ \\
\hline $\begin{array}{l}2 \text { unidades de cada, } \\
\text { sempre }\end{array}$ & Fio guia Hidrofílico & $\begin{array}{l}\text { 1)Terumo- fio guia mole, ponta “J” flexível, calibre } \\
\text { 0,035in, com comprimento de } 260 \mathrm{~cm} \text {, não stiff } \\
\text { 2)Roadrunner- fio guia mole, ponta “J” flexível de } \\
\text { 4,5cm, calibre de } 0,035 \mathrm{in} \text {, com comprimento de } \\
260 \mathrm{~cm}\end{array}$ & $\begin{array}{l}\text { Boston } \\
\text { Cook } \\
\text { E. Tamussino }\end{array}$ \\
\hline 1 unidade de cada & Fogarty & $\begin{array}{l}\text { Balão de desobstrução de números 2mm, 3mm, } \\
\qquad 4 \mathrm{~mm}, 5 \mathrm{~mm} \text { e } 6 \mathrm{~mm} \text {. }\end{array}$ & Fogarty \\
\hline
\end{tabular}




\section{Cateteres:}

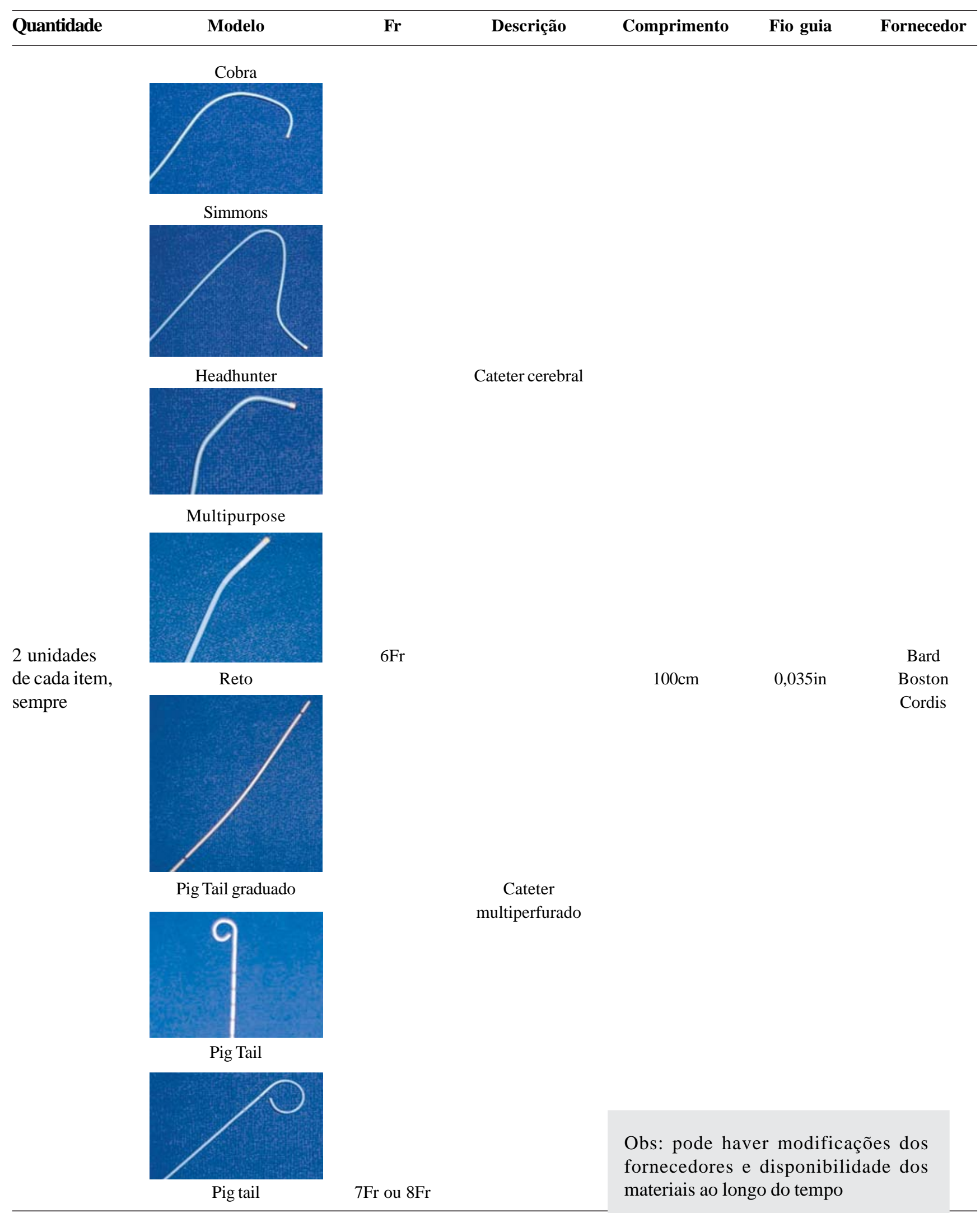


Balões de acomodação:

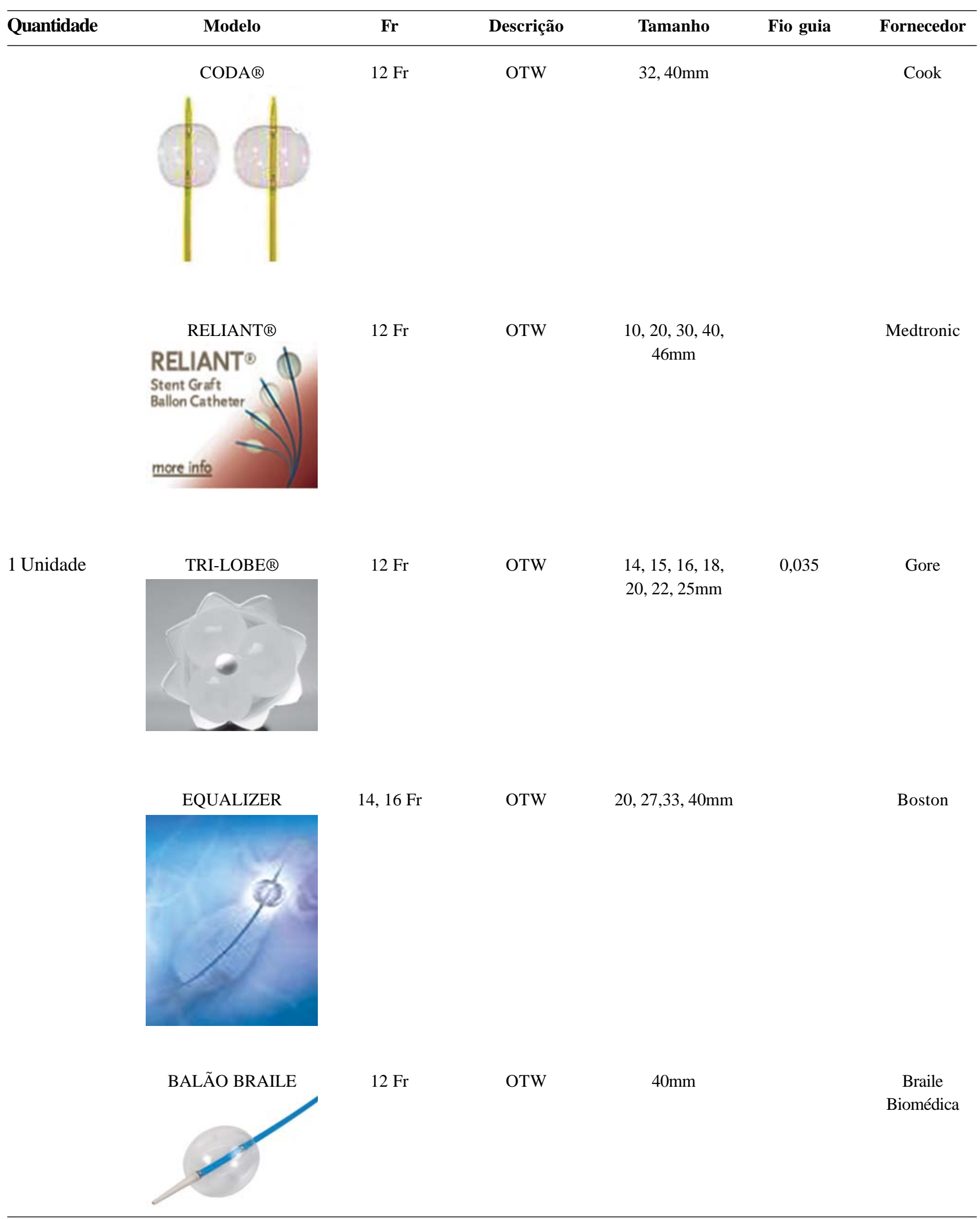


Endopróteses para tratamento endovascular dos aneurismas de aorta abdominal(AAA):

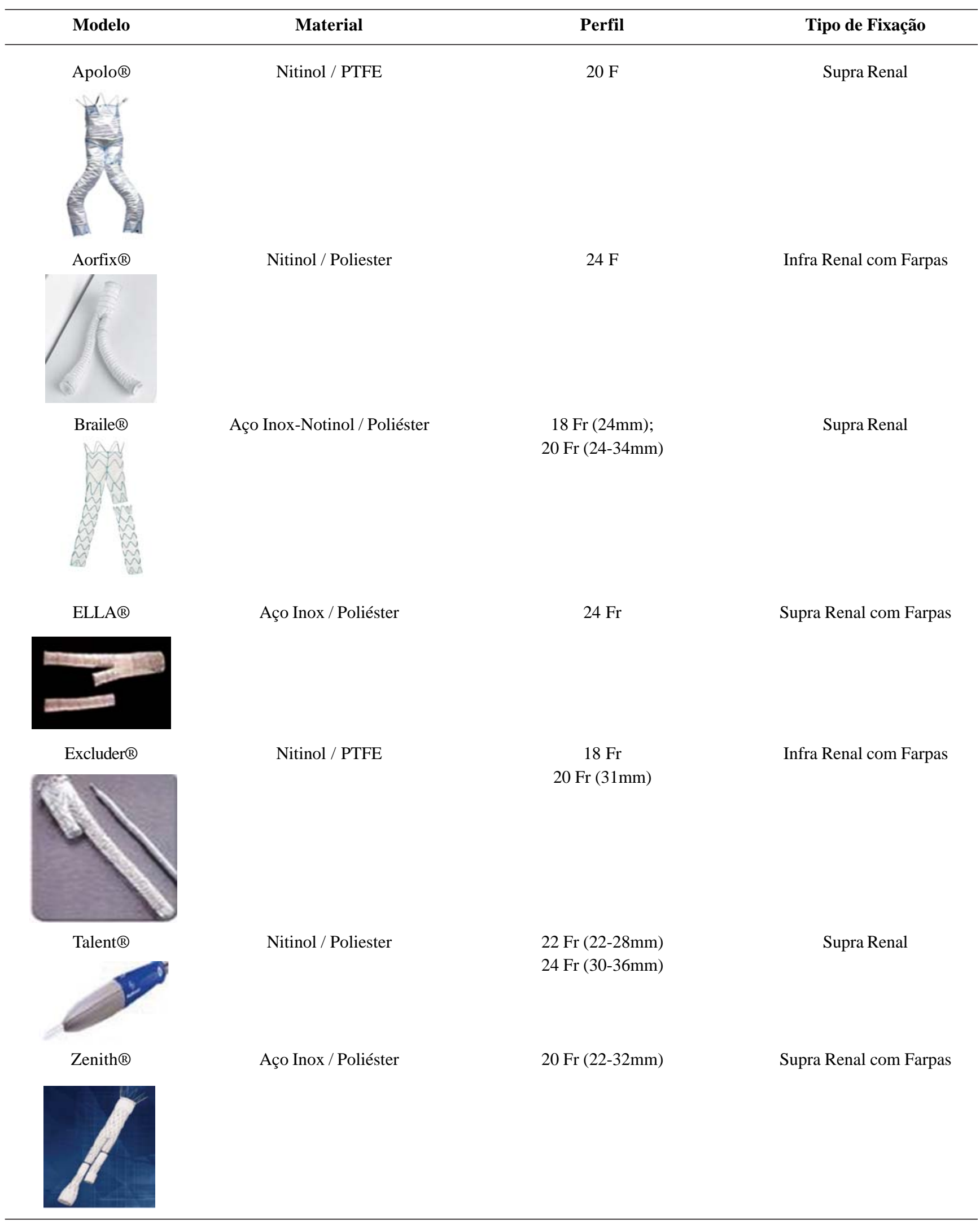

